\title{
empleos de las cenizas volantes en la construcción
}

\author{
les utilisations des cendres volantes dans la construction \\ annales de l'instlfut technique du batiment ef des travaux publics
}

M A. JARRIGE

(«12», núm. 138, Junio 1959, pág. 521.)

\section{GENERALIDADES}

Antes de entrar en detalles sobre las aplicaciones, el autor da algunas indicaciones generales y un breve resumen de las condiciones de producción y características de las cenizas.

Condiciones de producción de las cenizas volantes puestas a disposictón de los usuarios.

Las cenizas volantes provienen de la depuración de los humos de hogares que consumen carbón pulverizado. Las hogares que producen cenizas volantes representan hoy día la técnica más desarrollada en todo el mundo. Cierto número de centrales eléctricas alemanas producen cenizas fundidas (que se obtienen en estado húmedo y ligeramente granuladas). Este procedimiento está hoy en desuso. En Francia solamente lo aplica la central de Châlon.

Las cenizas volantes impalpables contenidas en los gases de combustión son recogidas, en la mayor parte de los casos, por vía seca a través de filtros electrostáticos y humedecidas después para facilitar su manutención y transporte en la descarga; no obstante, existen algunas instalaciones de captación por agua (Gennevilliers, Carling, etc.).
La producción de cenizas en una central es función de la potencia instalada, del contenido de inertes de los carbones empleados y del ritmo de marcha.

Según se empleen carbones muy ricos - productos de baja calldad, se obtienen de 25 a 300 gramos de cenizas volantes por $\mathrm{kWh}$ producido. Una central produce de 30 a 1.000 toneladas de cenizas volantes por día de marcha.

Las cenizas se ponen a disposición de los clientes a medida que se producen, en forma "seca" o "húmeda", y se transportan en "containers", en camiones-volquete o vagones. También pueden almacenarse las cenizas húmedas, sin mezclarse con otros materiales, para que se puedan cargar fácilmente cuando se necesitan.

Hay que hacer constar que algunas de las centrales existentes, por no haberse proyectado con vistas a vender las cenizas, han tenido que ejecutar importantes reformas para acondicionar los transportes.

La composición de las cenizas depende evidentemente de los carbones originarios; pero, en realidad, no existen diferencias apreciables entre las cenizas volantes producidas en distintos momentos por centrales alimentadas con combustibles de la misma cuenca hullera, lo que permite, en la mayoría de los casos, emplear unas u otras, indistintamente. 
No obstante, hay que diferenciar dos casos:

1) Es necesario distinguir entre las cenizas de hulla, siliceas, $y$ las cenizas de ciertos esquistos, calizas.

2) En todas las cenizas volantes se encuentran inquemados en mayor o menor cantidad, según el contenido en materias volátiles e inertes de los carbones consumidos y según el equipo de que disponen las calderas.

Se pueden clasificar las centrales, desde este punto de vista, en tres categorías:

- La categoría $A$, que da cenizas con 0 a $5 \%$ de inquemados.

-. La categoría $B$, que da cenizas con 5 a $10 \%$ de inquemados.

- Y la categoría C, que produce cenizas con un contenido de inquemados del 8 al $15 \%$.

El color de las cenizas, que es gris claro cuando son puras, se oscurece al aumentar su contenido en inquemados.

La experiencia de estos últimos años ha demostrado que puede desecharse toda preocupación de irregularidad enojosa en la calidad de las cenizas. En la mayoría de los casos, el suministro de una central puede ser considerado como de calidad estable; aun para su adición a los cementos, las irregularidades observadas no ofrecen dificultad.

\section{CARACTERISTICAS FISICAS $x$ QUIMICAS DE LAS CENIZAS}

Las cenizas producidas alrededor de los $1.500^{\circ} \mathrm{C}$ están constituídas, en gran parte, por una materia mineral vítrea y amorfa. Los granos se presentan en forma de esferitas macizas, bolas huecas y partículas metálicas. Tienen un tamaño medio de 40 micras, aproximadamente. Su finura es del orden de la de los cementos. Bastante friables, pueden molerse fácilmente a mayores finuras.

El peso específlco del material es del orden de 2,65 , pero esta cifra no se ob- tiene más que con productos muy finamente molidos; con cenizas en estado bruto o molidas a finuras intermedias, que contienen burbujas de aire, se obtienen pesos específicos aparentes de 1,85 a 2,4 .

Debido a su ligera y gran superficie específica, las cenizas volantes secas se arrastran con facilidad con una corriente de aire enérgica, lo que da origen a su nombre; su transporte por aire comprimido exige dispositivos de desaireación en el punto de llegada; no obstante, en atmósfera en calma, su transporte (por banda, microvibración o aerodeslizador) se efectúa sin producir polvo.

Las cenizas son aptas para absorber líquidos (agua, aceites, petróleo) y pueden aglomerarse bajo presión o por fuerza centrífuga gracias a la adherencia de las partículas entre sí o por intermedio de una película líquida.

Por ejemplo, la compacidad máxima se obtiene con 20 a $28 \%$ de agua. A partir de 40 a $50 \%$ de agua, las esferitas y los elementos muy finos permiten a las cenizas, aunque no tengan ninguna propiedad coloidal, desempeñar un papel de lubricante, mejorar la fluidez y manejabilidad de las mezclas en las que intervienen; a veces, presentan el inconveniente de producir una especie de lodo o barro.

Se encuentra la misma observación en las mezelas en seco de las cenizas con materiales de granulometría diferente. El problema se complica cuando intervienen a la vez un segundo material y un líquido.

\section{Fusibilidad.}

Calentadas en presencia de aire por encima de $680^{\circ} \mathrm{C}$ se quema el carbón retenido; a $750^{\circ} \mathrm{C}$ se oxidan las partículas ferruginosas y la ceniza toma un color salmón claro.

La temperatura de fusión de las cenizas depende de su composición química y oscila, según los casos, de $1.150^{\circ} \mathrm{C}$ a $1.450^{\circ} \mathrm{C}$. Esta fusión va precedida de un período de reblandecimiento bastante largo. La adición de ciertos compuestos 
(hierro, cal, álcalis, cloruros) intervienen notablemente sobre la temperatura de fusión.

Composición química.

Las cenizas volantes de hulla contienen una fuerte proporción de sílice $(50 \%)$ y alúmina $(30 \%)$, algo de óxido de hierro (7\%), muy poca cal $(2,5 \%)$ y algunos álcalis $(5 \%)$.

Las cenizas pueden ser utilizadas como fuente en la preparación de compuestos químicos:

- En la fabricación de pasta para crudos de cemento.

- En ciertos casos para la extracción de ciertos metales raros, el germanio, por ejemplo.

- Incluso se han realizado algunos ensayos para obtener industrialmente hierro y aluminio.

Actividad química.

Los elementos solubles contenidos en las cenizas se encuentran en cantidades extremadamente bajas; las cenizas en suspensión acuosa dan una reacción ligeramente alcalina. Para muchos usos corrientes se las considera prácticamente inertes; sin embargo, poseen una propiedad química característica: su poder puzolánico. Volveremos sobre el tema más detalladamente. Por el momento diremos que fijan la cal a la temperatura ordinaria, aunque con gran lentitud. Esta propiedad está influenciada por la flnura de las cenizas y de la cal, por la temperatura y por la presencia de productos minerales solubles. Esta propiedad se maniflesta con mayor actividad, aunque de forma todavía lenta, en presencia de la cal en estado naciente procedente de la hidratación del cemento. En algunos casos parece ser que la película exterior de los granos es absolutamente inerte, pero esta inactividad desaparece después de un ligero molido.
Para poner en evidencia la actividad puzolánica y para ver su comportamiento en su adición a los cementos, se han realizado en estos últimos tiempos numerosos ensajos químicos sobre las cenizas volantes. De ellos se hablará al tratar de los cementos con cenizas

\section{Inocuidad de las cenizas para las vias} respiratorias.

La facilidad de puesta en suspensión en el aire y la incomodidad producida por la respiración de este aire, habían creado clertas inquietudes ante el peligro que podrían representar estas materias minerales para los bronquios. Era necesario poner esta cuestión en claro. Los ensayos de larga duración realizados por laboratorios especializados alemanes $\mathrm{y}$ franceses demostraron que no existe ningún riesgo de silicosis en las personas que respiran estás cenizas. La manipulación de éstas no presenta, pues, ningún peligro para la salud. Es preferible tomar precauciones porque la suciedad del ambiente resulta desagradable, pero no hay razón para preocuparse ante posibles accidentes motivados por la formación de nubes de polvo.

\section{FMPLEO DE LAS CENIZAS VOLANTES COMO ARIDOS}

Vamos a examinar, en principio, algunas aplicaciones de las cenizas volantes que hacen referencia a sus propiedades físicas.

a) Las cenizas son muy indicadas para ser empleadas como material de relleno. Se las puede utilizar en la ejecución de terraplenes, en el relleno de huecos (por ejemplo, de viejos pozos o de canteras abandonadas), en el realce de terrenos, etcétera. En Holanda, en la región de los "polders", se han construido con cenizas volantes las plataformas elevadas sobre las que se han cimentado las edificaciones.

Se las emplea para el establecimiento de lechos cortafuegos en 
(hierro, cal, álcalis, cloruros) intervienen notablemente sobre la temperatura de fusión.

Composición química.

Las cenizas volantes de hulla contienen una fuerte proporción de sílice $(50 \%)$ y alúmina $(30 \%)$, algo de óxido de hierro (7\%), muy poca cal $(2,5 \%)$ y algunos álcalis $(5 \%)$.

Las cenizas pueden ser utilizadas como fuente en la preparación de compuestos químicos:

- En la fabricación de pasta para crudos de cemento.

- En ciertos casos para la extracción de ciertos metales raros, el germanio, por ejemplo.

- Incluso se han realizado algunos ensayos para obtener industrialmente hierro y aluminio.

Actividad química.

Los elementos solubles contenidos en las cenizas se encuentran en cantidades extremadamente bajas; las cenizas en suspensión acuosa dan una reacción ligeramente alcalina. Para muchos usos corrientes se las considera prácticamente inertes; sin embargo, poseen una propiedad química característica: su poder puzolánico. Volveremos sobre el tema más detalladamente. Por el momento diremos que fijan la cal a la temperatura ordinaria, aunque con gran lentitud. Esta propiedad está influenciada por la flnura de las cenizas y de la cal, por la temperatura y por la presencia de productos minerales solubles. Esta propiedad se maniflesta con mayor actividad, aunque de forma todavía lenta, en presencia de la cal en estado naciente procedente de la hidratación del cemento. En algunos casos parece ser que la película exterior de los granos es absolutamente inerte, pero esta inactividad desaparece después de un ligero molido.
Para poner en evidencia la actividad puzolánica y para ver su comportamiento en su adición a los cementos, se han realizado en estos últimos tiempos numerosos ensajos químicos sobre las cenizas volantes. De ellos se hablará al tratar de los cementos con cenizas

\section{Inocuidad de las cenizas para las vias} respiratorias.

La facilidad de puesta en suspensión en el aire y la incomodidad producida por la respiración de este aire, habían creado clertas inquietudes ante el peligro que podrían representar estas materias minerales para los bronquios. Era necesario poner esta cuestión en claro. Los ensayos de larga duración realizados por laboratorios especializados alemanes $\mathrm{y}$ franceses demostraron que no existe ningún riesgo de silicosis en las personas que respiran estás cenizas. La manipulación de éstas no presenta, pues, ningún peligro para la salud. Es preferible tomar precauciones porque la suciedad del ambiente resulta desagradable, pero no hay razón para preocuparse ante posibles accidentes motivados por la formación de nubes de polvo.

\section{FMPLEO DE LAS CENIZAS VOLANTES COMO ARIDOS}

Vamos a examinar, en principio, algunas aplicaciones de las cenizas volantes que hacen referencia a sus propiedades físicas.

a) Las cenizas son muy indicadas para ser empleadas como material de relleno. Se las puede utilizar en la ejecución de terraplenes, en el relleno de huecos (por ejemplo, de viejos pozos o de canteras abandonadas), en el realce de terrenos, etcétera. En Holanda, en la región de los "polders", se han construido con cenizas volantes las plataformas elevadas sobre las que se han cimentado las edificaciones.

Se las emplea para el establecimiento de lechos cortafuegos en 
los taludes del ferrocarril y como material de embarrado para la lucha contra el fuego en las minas. La presencta de inquemados no constituye una objeción, pues la ceniza realiza la estanqueidad de los materiales que le rodean, impidiendo la llegada del aire comburente.

Se puede hacer uso de ellas para el relleno de toda clase de fisuras, y en inyecciones (si se presenta el caso, mezcladas con el cemento) para contener vías de agua.

b) Los usos que acabamos de citar brevemente corresponden a la solución de problemas aislados, a operaciones discontinuas. El empleo de las cenizas como árido fino en la fabricación de bloques para la construcción $y$ en la confección de morteros y hormigones, representan, por el contrario, un consumo regular.

En Inglaterra se emplean grandes cantidades de cenizas en la fabricación de bloques de construcción.

Algunos empresarios franceses Ios utilizan también con éxito para piezas de chimenea y elementos prefabricados. En el espíritu de los usuarios, las cenizas volantes juegan un papel puramente mecánico o físico.

En este caso, las cenizas se transportan ligeramente húmedas $\mathrm{y}$ pueden almacenarse apiladas como la arena.

Los objetivos perseguidos son, según los casos, la economia, el aumento de compacidad y estanqueidad, la mejor presentación de los productos y-en ciertos casos-una mejora en la conservación del hormigón.

Al emplear las cenizas volantes en los hormigones se puede proponer, en primer término, la sustitución de una arena cara por un material más económico. Desde hace muchos años, en los trabajos de albañilería de las minas de hulla se reemplazan una parte de la arena por cenizas.
Pero el empleo de las cenizas volantes puede también conducir a preocupaciones de orden técnico.

De un modo general, las arenas de que se dispone para la preparación de morteros y hormigones son demasiado huecas, les faltan flnos; las cenizas, que son por el contrario muy finas, aportan a la arena un complemento granulométrico, IIenando los vacios entre los granos $y$, en consecuencia, mejoran la compacidad del hormigón. Las cenizas, por la forma esférica de sus partículas, mejoran la trabajabilidad de los morteros, llenan mejor las esquinas $\mathrm{y}$ ángulos de los moldes $\mathrm{y}$, por lo tanto, producen arístas más netas y superficies más lisas en los elementos con ellas fabricados.

No existe una regla general. Para tener una indicación de las dosificaciones a emplear es necesario proceder por tanteos.

Partiendo de una fabricación que emplea únicamente los áridos tradicionales, hay que hacer ensayos metódicos para determinar la proporción óptima de cenizas; por ejemplo: se confeccionarán probetas con dosificaciones variadas y se medirá en ellas su resistencia a comprestón, su densidad y porosidad.

Se han obtenido buenos resultados de resistencia mecánica en un hormigón que contenía, normalmente, 700 litros de grava, 500 litros de arena y 320 kilos de cemento (fig. 1).

En el gráfico, en abscisas están representados los pesos de cenizas, expresados en \% del peso total de la arena; y en ordenadas figuran:

a) La densidad del hormígón con adición de cenizas: la horizontal corresponde a la densidad de referencia: 2,35; la curva que representa las variaciones de densidad es la de trazo lleno.

b) La resistencla mecánica a las veinticuatro horas de los mismos hormigones: la horizontal representa la resistencia del hormigón de referencia: $145 \mathrm{~kg} / \mathrm{cm}^{2}$; la curva de las resistencias se representa en línea de trazos. 


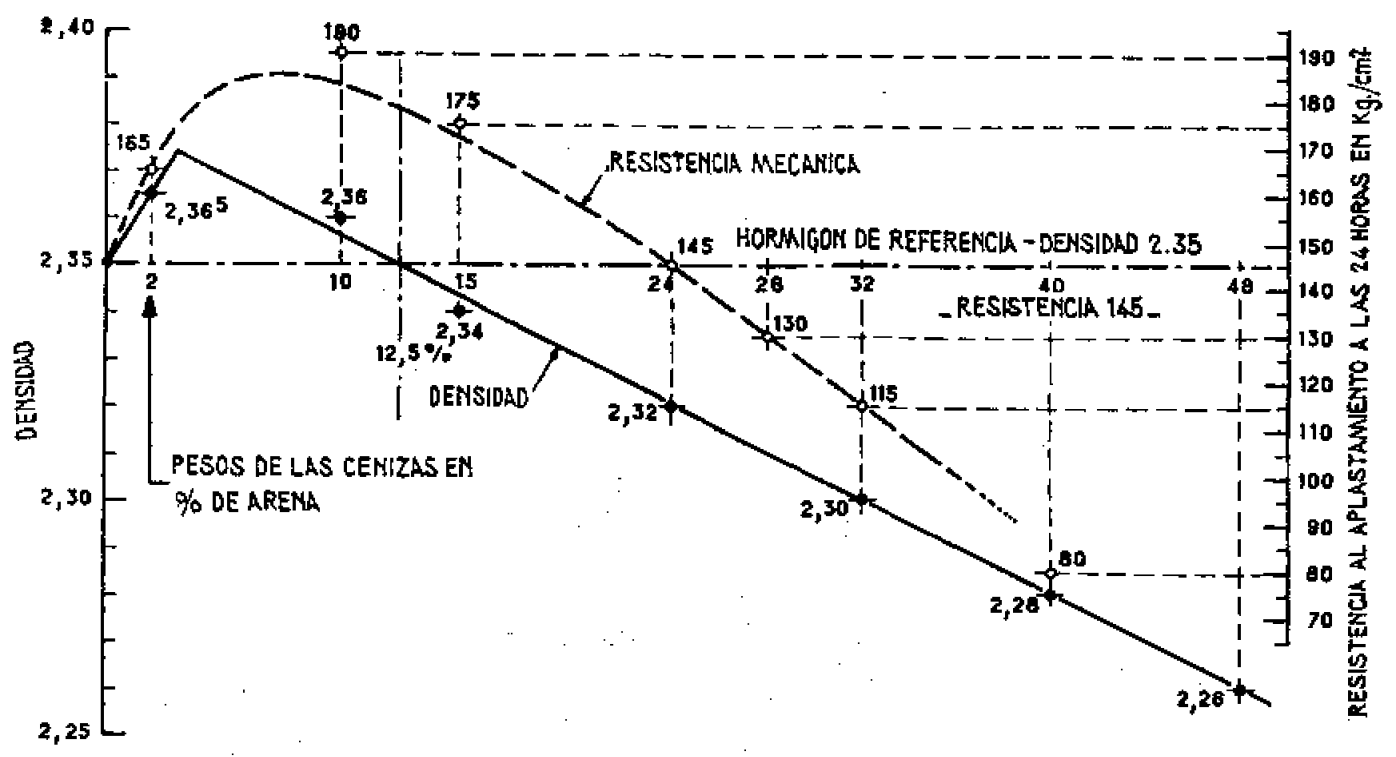

Variaciōn de la densidad del hormigón $\mathrm{y}$ de gu resintencia mecániea en fanción de la cantidad

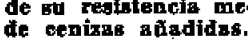

La forma de las curvas puede variar con las condiciones de la experiencia (características de los materiales, dosificaciones, edad del hormigón).

El llenado de los huecos existentes entre los granos de arena requiere una cierta cantidad de cenizas sin reducción de la arena, con el consiguiente aumento de peso. A partir de cierta proporción (3 a $7 \%$ ) todos los vacíos están ya llenos; si se agregan más cenizas, debe disminuirse la arena, y, como las cenizas son más ligeras, el peso específico total disminuye. Llega un momento en que, por llenado de huecos y reemplazamiento de arena, se observa una sustitución, peso a peso, sin variación de volumen. Esto se produce en los ensayos. del autor con el 12,5\% de cenizas. Si se continúa agregando cenizas se obtiene una disminución de la densldad del hormigón, con el consiguiente aligeramiento de los bloques. En el caso estudiado, con el $24 \%$ de cenizas se obtenía un aligeramiento de unos $30 \mathrm{~kg}$ por metro cúbico (175 $\mathrm{kg}$ de cenizas sustituyen a $205 \mathrm{~kg}$ de arena).

La máxima resistencia se obtenía con 8 a $10 \%$ de cenizas y era un $30 \%$ supe- rior a la del hormigón sin cenlzas. Con el $24 \%$ de cenizas se obtenía la resistencia del hormigón sin adiciones.

Es necesario llevar a cabo una mezcla cuidadosa para asegurar la repartición uniforme de las cenizas y evitar los grumos (mezclar áridos que se encuentran con el mismo grado de humedad y girar la hormigonera durante tres minutos, como mínimo).

Los hormigones resultan de un color gris-azulado. Algunos usuarios prefieren este color al gris claro del hormigón ordinario.

Los ensayos que se reseñan se hicieron en el año 1958. Durante los últímos meses se utilizaron varios miles de toneladas de cenizas para la confección de paneles prefabricados, con muy buenos resuitados técntcos y funancieros.

Muchos constructores no se preocupan de los áridos que emplean ni disponen de laboratorios organizados. Pero siempre tienen a su alcance el ensayo de sustituir $1 / 3$ de la arena por cenizas, ya que esto mejorará notablemente la manejabilidad del hormigón. 
Esta proporción se adoptó después de varios tanteos, sin gran rigor científico, dadas las calidades variables de Ios áridos empleados. Para una misma cantidad de agua se obtiene una mejora apreciable en la trabajabilidad del mortero. Esta fórmula es interesante en todas las obras públicas y privadas que se realicen en las cercanías de las centrales térmicas.

Hemos visto que la mejora de la compacidad debido al llenado de huecos aumenta, en cierta medida, la resistencia mecánica, pero hay que ser prudentes al pensar en disminuir la dosificación en cemento. El efecto puzolánico, que se maniflesta con retraso, no se toma de ordinario en consideración para la fabricación de elementos que exigen desmoldeo rápido. Aun en el caso de emplear las cenizas sin moler, esta propiedad puzolánica se manifestará después de un clerto tiempo y ofrecerá finalmente un interés para los productos fabricados que presentarán unas cualidades superiores de duración, mayor resistencia a las aguas agresivas y -en cierta medida-una menor retracción.

Ha llegado el momento de decir algo sobre las ventajas de la presencia de las cenizas en la conservación de los hormigones. Es bien conocido el hecho de que, al cabo de quince a veinticinco años, en las regiones industriales cuya atmósfera no siempre es pura, las superficies expuestas a la intemperie tienen tendencia a desmenuzarse, como consecuencia de la formación de fisuras y solubilidad de la cal del aglomerante. La adición de cenizas volantes puzolánicas entre el árido del hormigón de un elemento moldeado, contribuirá a fijar la cal y a poner a este elemento a cubierto de la acción disolvente de las lluvias.

Una revisión completa de las aplicaciones de las cenizas volantes en la construcción debería comprender algunos capítuIos sobre el empleo de las cenizas como desengrasantes de la pasta para ladrillos, como materia prima para la fabricación de hormigones celulares y como carga de los plásticos. Estos empleos los citaremos brevemente a continuación.
Desengrasantes en la pasta de ladrillos.

Algunos ensayos de empleo de las cenizas, en sustitución de la chamota para desengrasar las arcillas plásticas, han dado resultados muy favorables con porcentajes que alcanzan el $85 \%$ de cenizas, en el caso de arcillas muy plásticas.

Las aplicaciones industriales, según nuestro conocimiento, no han ido tan lejos. En Inglaterra, se hacen ladrillos con el $50 \%$ de cenizas. En Francia, algunos ladrilleros emplean de 15 a $25 \%$ de cenizas.

Hormigón celular.

En los hormigones celulares, crudos o sometidos a autoclave, las centzas desempeñan el doble papel de áridos y agentes puzolánicos.

\section{Carga para plásticos.}

Estos últimos años se ha producido un aumento grande en el consumo de materiales plásticos para la construcción. Se prevé más consumo para un porvenir próximo. Ciertas reservas se deben a su alto precio y podrian superarse mediante el empleo de cargas más económicas. Las cenizas volantes se prestarian muy bien a este fin. Los pequeños modelados realizados con cenizas tostadas (color salmón) o sin tostar (color gris oscuro) tienen una bella apariencia.

\section{Cenjzas sinterizadas como arfdo ligero.}

Después de hablar del empleo de las cenizas (consagradas ya en Francia por cierta práctica), vamos a decir algunas palabras sobre un tratamiento experimentado en Inglaterra y en Alemania: la aglomeración de las cenizas por sinterización, es decir, por pegadura de los granos en un reblandecimiento a temperatura algo inferior a la de su fusión, utilizando como combustible los inquemados que contienen las propias cenizas. 
Se obtiene así, bajo la forma de una especie de clínker, de escorias o de bolitas, un arido resistente y relativamente ligero, de una densidad aparente del orden de 0,6 ó 0,7, análoga a la de la puzolana, que puede, en muchos usos, reemplazar a la grava ordinaria.

Ios productos obtenidos por fabrica. ción, tanto artesana como semi-industrial o industrial, cumplen a satisfacción desde el punto de vista técnico: la experiencia inglesa de los dos últimos años lo ha demostrado. La puesta a punto de las instalaciones capaces de resolver económicamente todas las exigencias de una fabricación industrial parece que todavía no se ha logrado, pero es de esperar que se consiga. El día que se superen las tiltimas diffcultades se resolverán al mismo tiempo, y a satisfacción de los unos y de los otros, los problemas de evacuación de las cenizas de numerosas centrales y los de aprovisionamiento de grava y puzolanas de los constructores que trabajan en las cercanías de estas centrales.

El procedimiento exige un contenido de inquemados superior al $5 \%$. A los cementeros, sin embargo, les interesan principalmente las de contenidos inferiores, por lo que no se corre el riesgo de una posible competencia.

\section{UTILIZACION EN CARTETERAS}

La utilización de las cenizas en carreteras constituye un intermedio entre la sustitución de áridos y su incorporactón como constitutivo de los aglomerantes.

En América, los principales empleos industriales de las cenizas volantes son dedicados a las carreteras, sobre todo como filler de los aglomerantes bituminosos, a razón de 3 a 400.000 toneladas por año, así como otras importantes cantidades para la estabilización de suelos y ca rreteras de hormigón.

En el curso de un coloquio celebrado en el Laboratorio de Puentes y Carreteras, con el fin de estudiar y resumir las ideas y experiencias sobre el empleo de las cenizas en las carreteras, se ha llegado a las siguientes conclusiones: a) Las cenizas volantes pueden ser empleadas solas como subcapas de protección para evitar el paso de arcilla a capas superiores; su facilidad de compactación y su porosidad permiten la construcción de Iechos filtrantes; los pequeños intervalos libres entre las partículas dificultan el paso de las suspensiones de arcilla por capilaridad. De hecho, en las obras se observa una excelente estanqueidad de las capas de cenizas compactadas; los efectos del hielo no se manifiestan después de varios años de ejecución. No obstante, el empleo de las cenizas según esta fórmula será probablemente bastante limitada.

b) El efecto de superficie de las centzas volantes permite utilizarlas para espesar los aglomerantes hidrocarbonados, en sustitución, total o parcial, de los fillers calizos habituales o en mezcla con una pequeña cantidad de cal, en la ejecución de revestimientos densos.

El precio económico de las cenizas permite aumentar la dosificación de filler, lo que se considera actualmente como medio de mejorar la calidad de los revestimientos.

El empleo de las cenizas parece particularmente indicado en el caso de los alquitranes.

c) Las cenizas son utilizables para la estabilización, tanto mecánica como química, de los suelos.

En la estabilización mecánica, por su granulometría fina, permiten rellenar los huecos entre los granos más gruesos que componen las arenas, gravas y esquistos de los terrenos "in situ" y mejorar, por abovedamiento mutuo, su resistencia a la compresión.

Si se adicionan cenizas a un aglomerante hidráulico con el fin de producir una estabilización química, su efecto puzolánico, aunque lento, permite disminuir la do- 
sificación del aglomerante y extender o ampliar el dominio de empleo económico del procedimiento. Indirectamente, las cenizas suministran un medio de dispersión fácil del aglomerante; es más cómodo repartir de manera uniforme un material magro en el que las cenizas representan el $12 \%$ del volumen total del terreno, que el $3 \%$ de cemento puro. De otro lado, para evitar los riesgos de fisuras, no interesa emplear un aglomerante demasiado bueno; entonces puede convenir emplear un cemento con un $75 \%$ de cenizas, siendo posiblemente más ventajoso prepararlo sobre el terreno que fabricarlo por las factorias de cemento. Algunos consideran que la mezcla de las cenizas con cal (lime-flyash) es preferible porque no es necesario ponerlo en obra tan rápidamente.
La Dirección del Laboratorio de Puentes y Carreteras y la Dirección de Pistas han tomado bajo su protección el empleo de las cenizas en las carreteras; esto tendrá un efecto estimulante en el desarrollo de esta técnica, particularmente en la estabilización mecánica y química de los suelos.

El Laboratorio de Puentes y Carreteras ha decidido la creación de un polígono de ensayos para estos materiales en las condiciones prácticas de obra. Tales experiencias suministrarán unas enseñanzas muy preciosas sobre el comportamiento de las cenizas. Es de esperar que sean puestas en marcha próximamente, para poder sacar pronto provecho de los resultados.

(Continuará.)

F. S. S.

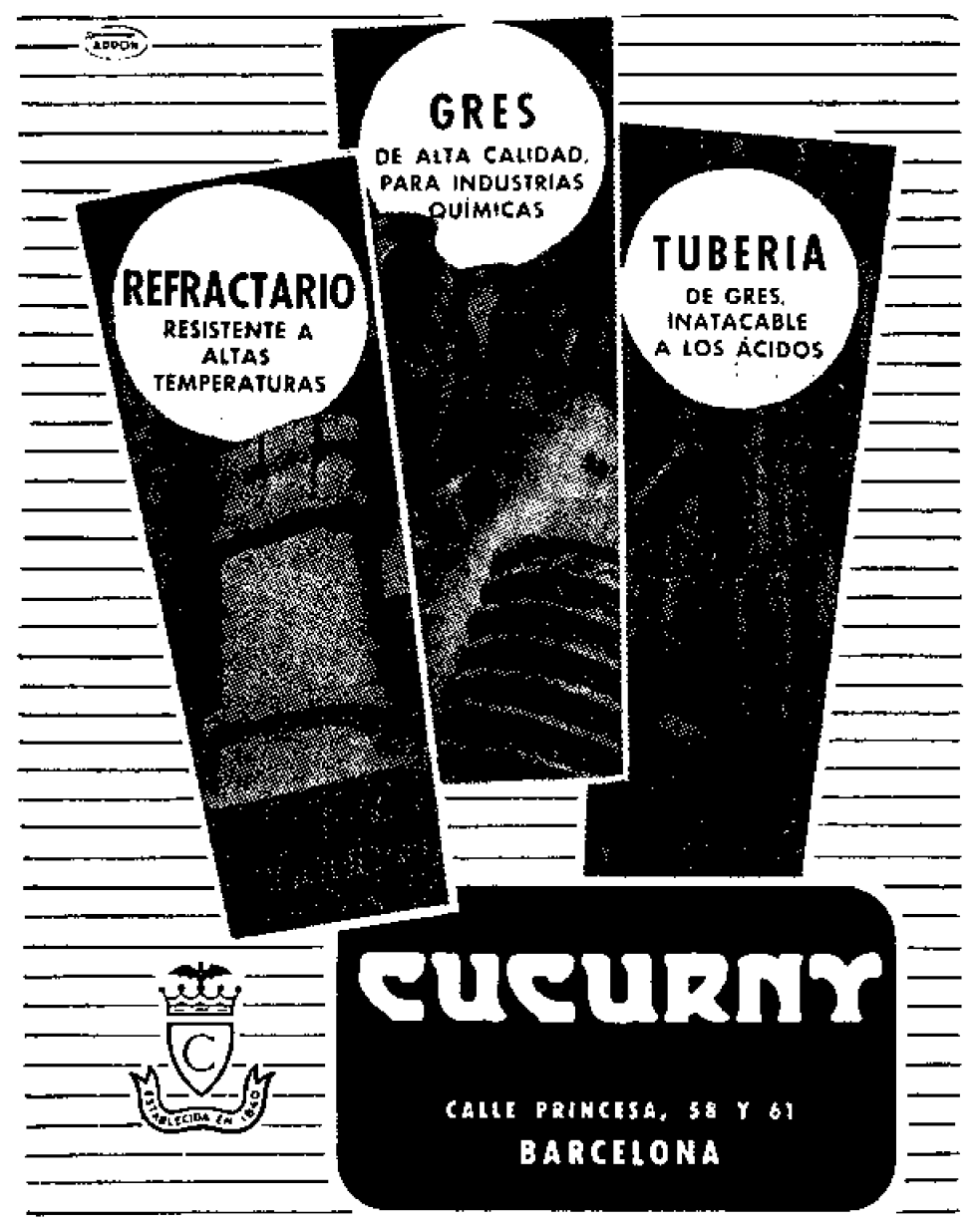

